\title{
EPIDEMIOLOGICAL DATA ON THE DETECTION OF IMMUNOGLOBULINS OF CLASS IGM, IGG TO SARS-COV-2 AMONG POPULATION OF POLTAVA REGION
}

DOI: $10.36740 /$ WLek202105116

\author{
Alla V. Marchenko, Maiia M. Ananieva, Mariia 0. Faustova, Galina A. Loban', Iryna Yu. Lytovchenko, \\ Ihor A. Nikolishyn, Nataliia V. Ilenko-Lobach \\ UKRAINIAN MEDICAL STOMATOLOGICAL ACADEMY, POLTAVA, UKRAINE
}

\begin{abstract}
The aim: Of this study was to analyze epidemiological data on the detection of immunoglobulins of class M and G (lgM, lgG) to SARS-CoV-2 among urban and rural population of Poltava region.

Materials and methods: We have analyzed the research results of 2841 patients to determine lgM and lgG levels to SARS-CoV-2. The study included the results of patients in Poltava and nearby villages of Poltava region, obtained during July - December 2020.

Results: Thus, $84 \%$ of patients applied for detection of IgM in the serum of patients with the pathogen COVID-2019. We have found only 135 positive results for the detection of IgM to SARS-CoV-2, which was $5.7 \%$ of the total number of people who underwent this study from July to December 2020 . Moreover, women received a positive result more often than men. The IP samples for the detection of IgM to SARS-CoV-2 in the serum of patients averaged $2.5 \pm 1.04$.

It was found that patients went to the laboratory to detect lgG to SARS-CoV-2 with the vast majority among them were residents of Poltava. However, in this case the share of positive results was $47.7 \%$, among which the female population outnumbered the male.

Conclusions: The frequency of detection of positive results on IgM to SARS-CoV- 2 is about $6 \%$. The share of positive results on IgG to SARS-CoV- 2 was $47.7 \%$, among them $76.2 \%$ were women. The frequency of detection of $\mathrm{lgM}$ and $\mathrm{lg} G$ to SARS-CoV-2 during 0ctober-December 2020 significantly exceeds the indices in July-September of the same year.
\end{abstract}

KEY WORDS: IgG, IgM, SARS-CoV-2, COVID-2019, frequency

Wiad Lek. 2021;74(5):1134-1136

\section{INTRODUCTION}

Coronaviruses (CoVs) are a group of complex viruses that are characterized by high mutation rates and infectivity. They are zoonotic pathogens that affect both animals (wild/domestic) and humans, followed by the development of acute respiratory syndrome in about $10 \%$ of cases $[1,2]$. Previously, coronaviruses were not included in the list of dangerous human pathogens. However, at the beginning of the 21st century, two members of this virus family - SARS-CoV and MERS-CoV caused global epidemics of pneumonia with a high mortality rate $[1,3]$. Moreover, 7 years after the last outbreak of the coronavirus epidemic (2012) humanity faced a rapid spread of cases of severe atypical pneumonia caused by a new strain of coronavirus SARS-CoV-2 in December 2019 [4].

Up to now, according to the WHO, about 6 million people in more than 210 countries have been exposed to the disease caused by this pathogen - COVID-2019 [5]. The mortality rate for this disease is not much higher than for SARS-CoV and MERS-CoV. However, the new pathogen is characterized by higher infectivity and contagiousness and, as a consequence, faster human-to-human transmission. Namely abovementioned features contributed to the spread of the SARS-CoV-2 virus to all continents, causing the global COVID-2019 pandemic $[1,6]$.
The epidemiological situation regarding COVID-2019 is constantly changing. If previously it was thought that the virus mainly affects people in China and neighbouring countries, today the leaders in the incidence of coronavirus are the United States and Brazil. Moreover, the mortality rate varies significantly in different countries. Thus, countries with low testing capacity, imperfect health care systems, and lack of clear emergency behaviour strategies show significantly higher mortality rates than COVID-2019 [5, 7].

Statistical data concerning the presence of antibodies to SARS-CoV-2, collected from different countries, differ significantly not only from each other but also within one country at different times. After all, when analyzing WHO reports, patients with mild COVID-2019 have almost no IgG for coronavirus. Whilst in severe forms of the disease immunoglobulins disappear on average within 3-4 months. It should be noted that the genetic relatedness of different types of CoVs also negatively affects the determination of antibody levels in patients due to the frequent development of cross-reactions $[5,8]$.

That is why, on the way to overcoming the pandemic that engulfed humanity in 2020, the strategic vector is to monitor the formation of population immunity among re-convalescents and the development of an effective vaccine [5]. 


\section{THE AIM}

The aim of this study was to analyze epidemiological data on the detection of immunoglobulins of class $\mathrm{M}$ and $\mathrm{G}$ (IgM, IgG) to SARS-CoV-2 among urban and rural population of Poltava region.

\section{MATERIALS AND METHODS}

We have analyzed the research results of 2841 patients to determine IgM and IgG levels to SARS-CoV-2. The study was conducted using ELISA kits for qualitative detection of antibodies of IgM and IgG classes to SARS-CoV-2 virus (EQUI SARS-CoV-2 IgM, IgG), produced by EKVITESTLAB LLC, Ukraine. The evaluation of the results was performed according to the index of positivity of the sample (IP), the value of which is more than 1.1 was defined as a positive result.

The study included the results of patients in Poltava and nearby villages of Poltava region, obtained during July December 2020.

In order to determine the epidemiological data on the detection of IgM and IgG to SARS-CoV-2 among urban and rural population of Poltava region, patients were divided by place of residence (city, village), sex, and detection of immunoglobulins in the study.

The results were provided by a private certified laboratory in Poltava while maintaining the confidentiality of patients' personal data.

The studies have been carried out in accordance with the Helsinki Declaration of the World Medical Association on the ethical principles of medical research with human participation. The study protocol was approved by the Bioethics Committee of the Ukrainian Medical Stomatological Academy, Poltava, Ukraine.

The obtained data were subjected to statistical processing using the standard program SPSS 16.0 software (IBM, Armonk, NY, USA) and expressed as the arithmetic mean $(\mathrm{M})$ and the arithmetic mean error $( \pm \mathrm{m})$. The presence of differences between the indicators of the studied groups of patients was assessed by Student's t-test. The results were considered reliable at $\mathrm{p}<0.05$.

\section{RESULTS}

As a result of the study, it was found that during the summer-autumn period of 2020, a study to detect total antibodies (IgM, IgG) to SARS-CoV-2 among urban and rural population of Poltava region was conducted by 6 people, which is $0.2 \%$ of the total number of surveyed. In spite of all this, no positive results were found among them.

The vast majority of studies were the results of the detection of IgM in the serum of patients with the pathogen COVID-2019. Thus, $84 \%$ of patients applied for this study, i.e., 2375 patients out of 2841 . This confirms the greater demand for research to detect antibodies corresponding to the acute period of the disease. It should be noted that the vast majority of people $(2185,77 \%)$ were residents of Poltava and only 190 (7\%) patients were from rural areas.
We have found only 135 positive results for the detection of IgM to SARS-CoV-2, which was $5.7 \%$ of the total number of people who underwent this study from July to December 2020. Moreover, women received a positive result 1.7 times more often than men ( 85 and 50 people, respectively). In addition, the frequency of negative IgM results for the pathogen COVID-2019 was 94.3\%, but in this case, on the contrary - women received a negative result 1.5 times more often than men. The IP samples for the detection of IgM to SARS-CoV-2 in the serum of patients did not exceed 9.53 and averaged $2.5 \pm 1.04$.

Analyzing seasonal prevalence, we have found an increase in the incidence of IgM to SARS-CoV-2 during October - December by 8 times compared to July-September.

As a result of the study, it was found that patients went to the laboratory to detect IgG to SARS-CoV-2, 5 times less often (468 people), with the vast majority $(445,95 \%)$ among them were residents of Poltava. However, in this case the share of positive results was $47.7 \%$, among which the female population $(170,76.2 \%)$ outnumbered the male 3.2 times. In turn, among the 245 negative IgG results to the pathogen COVID-2019, 132 were obtained from men. That is, in this case, males were 1.2 times more likely to go to the laboratory for IgG, compared with women. Interestingly, the maximum IP for the detection of IgG to SARS-CoV-2 in the serum of patients did not exceed 8.0 and averaged $6.05 \pm 1.95$.

The frequency of IgG detection to SARS-CoV-2 during October-December 2020 increased 17.5 times compared to July-September of the same year.

\section{DISCUSSION}

Unconditionally, city residents applied to the laboratory more often to detect antibodies against coronavirus disease, which can be explained by both logistics difficulties (the need to move to the city or transportation the material in case of absence of a laboratory in the village) and financial problems.

From the obtained results, it is evidently seen that women turned to the laboratory for the detection of IgM antibodies to SARS-CoV-2 more often. For all that the vast majority of them received negative results. It indicates a higher level of anxiety, which develops against the background of stress in women compared to men. It is considered that this may be due to the neurophysiological characteristics of women associated with the relationship of low activity of enzymes that regulate catecholamine mediator systems and instability under stress $[9,10]$.

In their turn, men were more often interested in detecting IgG to SARS-CoV-2, which indicates a disease. According to the research, males have a more stable level of anxiety and resilience in stressful situations, so the search for late antibodies was aimed at confirming the probable asymptomatic transmission of the disease. Due to our studies, the frequency of negative results among men was high $[9,10]$.

It should be noted that the number of positive results for IgM and IgG in general to SARS-CoV-2 during July - 
September was significantly lower than in October - December. On the one hand, such a result could be influenced by weather conditions, noticing the warm beginning of autumn in Ukraine. After all, COVID-2019 belongs to the diseases that is transmitted by airborne droplets and often develops at low ambient temperatures.

However, on the other hand - analyzing the quarantine measures to prevent the spread of coronavirus in Ukraine during this period, we can trace a certain trend. Thus, during the summer there was a weakening of preventive measures, which contributed to the return of pupils and students to educational institutions on September 1, and employees - in offices and businesses. Moreover, on September 23, Poltava and its citizens celebrated the Day of Liberation of the city in the Second World War with active mass events. Given the data on the incubation period COVID-2019, it becomes quite natural to develop the peak incidence since October.

\section{CONCLUSIONS}

Thus, residents of Poltava and surrounding villages more often turn to laboratories to detect IgM to SARS-CoV-2, with mostly negative results.

The frequency of detection of positive results on IgM to SARS-CoV-2 is about 6\%. The share of positive results on IgG to SARS-CoV-2 was $47.7 \%$, among them $76.2 \%$ were women.

The frequency of detection of IgM and IgG to SARSCoV-2 during October-December 2020 significantly exceeds the indices in July-September of the same year.

\section{REFERENCES}

1. Hozhabri H., Piceci Sparascio F., Sohrabi H. et al. The Global Emergency of Novel Coronavirus (SARS-CoV-2): An Update of the Current Status and Forecasting. Int J Environ Res Public Health. 2020;17(16):5648.

2. Zumla A., Chan J.F., Azhar E.I. et al. Coronaviruses-Drug discovery and therapeutic options. Nat. Rev. Drug Discov. 2016; 15: 327-347.

3. Chan J.F., Lau S.K., Woo P.C. The emerging novel Middle East respiratory syndrome coronavirus: The "knowns" and "unknowns". J. Formos. Med. Assoc. 2013; 112: 372-381.

4. Zhu N., Zhang D., Wang W. et al. China Novel Coronavirus Investigating and Research Team. A Novel Coronavirus from Patients with Pneumonia in China, 2019. N. Engl. J. Med. 2020; 38; 727-733.

5. Ortiz-Prado E. et al. Diagnostic Microbiology and Infectious Disease. 2020; 98: 115094.

6. Coronaviridae Study Group of the International Committee on Taxonomy of Viruses. The species Severe acute respiratory syndrome-related coronavirus: Classifying 2019-nCoV and naming it SARS-CoV-2. Nat. Microbiol. 2020; 5; 536-544.
7. Simbana-Rivera K., Gomez-Barreno L., Guerrero J. et al. Interim analysis of pandemic Coronavirus Disease 2019 (COVID-19) and the SARS-CoV-2 virus in Latin America and the Caribbean: morbidity, mortality and molecular testing trends in the region. medRxiv 2020; 25:20079863.

8. Pang J., Wang M.X., Ang I. et al. Potential Rapid Diagnostics, Vaccine and Therapeutics for 2019 Novel Coronavirus (2019-nCoV): A Systematic Review. J. Clin. Med. 2020; 9:623.

9. Tushkova K.V., Bundalo N.L. Reaktyvnaia y lychnostnaia trevozhnost u muzhchyn y zhenshchyn pry posttravmatycheskom stressovom rasstroistve razlychnoi stepeny tiazhesty [Reactive and personal anxiety in men and women with post-traumatic stress disorder of varying severity]. Syb. med. obozrenye. 2013; 3(81): 89-93.

10. Petrushanko T. A., Chereda V. V., Loban G. A. The Relationship Between Colonization Resistance of the Oral Cavity and Individual-Typological Characteristics of Personality: Dental Aspects. Wiadomosci lekarskie (Warsaw, Poland: 1960). 2017; 70(4): 754-757.

The work is a fragment of the research project "Study of the role of opportunistic and pathogenic infectious agents with different sensitivity to antimicrobial and antiviral drugs in human pathology" state registration No. $0118 U 004456$.

\section{ORCID and contributionship:}

Alla V. Marchenko: 0000-0003-2178-6383 A, E, F

Maiia M. Ananieva: 0000-0001-9435-7622 B,C

Mariia O. Faustova: 0000-0001-5327-6324 ${ }^{C, D}$

Galina A. Loban': 0000-0003-0055-7696 ${ }^{F}$

Iryna Yu. Lytovchenko: 0000-0002-3505-1057 ${ }^{\mathrm{E}}$

Ihor A. Nikolishyn: 0000-0001-7984-3411 ${ }^{\mathrm{C}}$

Nataliia V. Ilenko-Lobach: 0000-0001-9213-9883 C

\section{Conflict of interest:}

The Authors declare no conflict of interest.

\section{CORRESPONDING AUTHOR Alla V. Marchenko Ukrainian Medical Stomatological Academy 23 Shevchenko st, 36011 Poltava, Ukraine tel; +380506059436 \\ e-mail: allamarchen@ukr.net}

Received: 09.12.2020

Accepted: 31.03 .2021

A - Work concept and design, B - Data collection and analysis, C - Responsibility for statistical analysis, D-Writing the article, $\mathbf{E}-$ Critical review, $\mathbf{F}$ - Final approval of the article 


\title{
STRENGTHENING SOCIETAL RESILIENCE DURING COVID-19 PANDEMIC
}

DOI: 10.36740/WLek202105117

\author{
Andriana M. Kostenko, Nina D. Svitailo, Mykola S. Nazarov, Viktoriya S. Kurochkina, Yevhen V. Smiianov
}

SUMY STATE UNIVERSITY, SUMY, UKRAINE

\begin{abstract}
The aim: To investigate factors that can negatively affect societal resilience in the context of the COVID-19 pandemic and identify communication aspects of strengthening resilience through information policy formation.

Materials and methods: In the research process, the authors employed the monographic and abstract-logical methods. The communication aspect analysis of strengthening social resilience in the context of the COVID-19 pandemic also grounded upon the results of the authors' sociological study "Motivation of compliance/non-compliance with quarantine restrictions by the population of Ukraine". Focus-group interviews and surveys. A total of 1,700 respondents represent the adult population of Ukraine aged 18 and older (except those living on the territory temporarily not controlled by the Ukrainian authorities - the Autonomous Republic of Crimea, some areas of Donetsk and Luhansk regions). The error of the study representativeness with a probability of 0.95 : does not exceed $4 \%$.

Results: The analysis results indicate that under pandemic conditions informational space of Ukraine is charging with low-quality and diverse information and is getting out of control, which entails adverse effects on societal resilience. Besides, a survey conducted by the SSU Center for Social Studies endorses the availability of communication gaps. The poll claims $38.6 \%$ of Ukrainians to be dissatisfied with their awareness level of Covid-19 because the information is contradictory and unreliable. The opinion poll also proves the low level of Ukrainians' trust in state institutions and official details on the Covid-19 pandemic. Furthermore, violations of quarantine restrictions are socially acceptable, and a significant part of the population tends to ignore such violations by others. That is, among Ukrainians, compliance with quarantine restrictions has not become a social norm. Conclusions: An essential component for molding social resilience is the development and adoption of communication policies to change human behavior in the long-term in the context of the COVID-19 pandemic. The government should also develop a Public Health Awareness Concept in the pandemic with appropriate implementation plans at the state, regional and territorial community levels.
\end{abstract}

KEY WORDS: healthcare institutions, societal resilience, COVID-19, communication, civil society

Wiad Lek. 2021;74(5):1137-1141

\section{INTRODUCTION}

Amid turbulence and economic crisis caused by the COVID-19 pandemic, states have to revise their development forecasts, approaches to implementing social or economic policy, and look for new societal resilience management models at both national and local levels.

Social (or societal) resilience is an integral part of national stability. It is defined as a nation-state preserving ability regarding its societal cohesion when confronted by external and internal stresses caused by socio-political changes and/ or violent disturbance [1]. By resilience, we mean a society's ability to resist and recover from crises and perturbations easily and quickly, the ability to develop or adapt to drastic and potentially long-term changes. Moreover, the changes themselves can give rise to new norms. In this case, societal resilience should envisage new rules rather than resist them [2].

The formation of social resilience requires not only taking measures from the state but also social capability. The ongoing Ukrainian society development stage implies additional challenges because the characteristic confrontation between the government and civil society in the pandemic has intensified dramatically. Simultaneously, the lack of communication strategy capable of minimizing risks and shaping the necessary community cohesion in the face of everyday challenges has become even more pronounced. The media actively broadcasts the message of insufficient responsibility of the population, constant violations of quarantine requirements, regarded by the government and health authorities as one of the main factors determining the critical dynamics of the disease expansion and the similar critical situation in hospitals. Along with this, citizens do not trust the official information about COVID-19 too much. The critical distrust in the government exacerbates the problem at all levels, which results in the unwillingness to comply with quarantine restrictions. In this situation, state policy relating to vaccination or applying restrictive measures is complicated by the lack of a systematic communication policy to build social resilience in the face of uncertainty about the coronavirus pandemic.

\section{THE AIM}

To analyze the factors that can negatively affect societal resilience in the pandemic and identify communication aspects of strengthening resilience through information policy molding. 
The practical significance of the results. This study's main provisions can be used to form a model for developing communication strategies to strengthen social capital and create social resilience in Ukraine.

\section{MATERIALS AND METHODS}

The study used a monographic method (analysis of Ukrainian and foreign scientific achievements on social resilience and social capital development problems) and an abstract-logical method (theoretical generalizations and formulation of conclusions). The analysis of communication aspects of strengthening social resilience under the COVID-19 pandemic was also carried out based on the results of the authors' sociological study "Motivation of compliance/non-compliance with quarantine restrictions by the population of Ukraine".

An all-Ukrainian sociological study was conducted in late 2020 by the Center for Social Studies of Sumy State University [3]. Methods: focus-group interviews and questionnaires (surveys). A total of 1,700 respondents representing the adult population of Ukraine aged 18 and older (except for those living on the territory temporarily not controlled by the Ukrainian authorities - the Autonomous Republic of Crimea, some areas of Donetsk and Luhansk regions). The error of the study representativeness with a probability of 0.95 : does not exceed $4 \%$.

Quota sampling: quotas by sex, age, region, size of the settlement. Respondents were randomly selected in four clusters of Ukraine: Western, Central, Southern, and North-Eastern. A specially designed questionnaire was used as a tool, formed in light of the focus-group study results conducted at the previous stage.

\section{RESULTS}

Violation of quarantine restrictions by the population is one of the threats that can worsen the epidemiological and, consequently, the country's socio-economic situation. Studies by Paola Giuliano and Imran Rasul [4] confirm that social capital, the level of trust in government and institutions, and media sources used by the population are essential in quarantine compliance. We believe that these are decisive factors in the formation of societal resilience as well. Therefore, let us analyze the specified characteristics of social stability and determine the communication aspects of strengthening resilience in the Covid-19 pandemic.

Under social capital, scholars understand "networks, shared norms, values, and insights that facilitate collaboration within or among groups" of the population [5]. Recognizing social capital as one of the elements of interaction between society and state institutions, which determines a country's development level and positioning at the international level [6], researchers pinpoint the importance of active and conscious construction of such interaction in society [7-9].

It is the system of broad and reliable informing citizens on fundamental processes taking place in society, govern- ment and self-government activity, and the public sector that plays a decisive role in building such interaction, formed on the basis of shared norms and values.

It is just about the systematic nature of such information, which should be based not only on relevant institutions such as independent media or select communication channels. With their help, the government distributes required information, the legislative framework for freedom of expression, etc. There should also be an appropriate level of trust in such sources and public confidence in the government, which is also one of the conditions for information security and social resilience.

It is worth highlighting that through social networks, accepted social norms, and trust, it is social capital that creates conditions for cooperation and collaboration between different actors, whose benefit obtains everyone. And the lack of such trust and partnership is characteristic not only of the Ukrainian society [10].

The crises generate a complete consolidation of the human and social factors in developed countries. They are a catalyst for deepening the social situation in the countries with economies in transition. At the same time, we can expect that the crisis brought on by the pandemic is capable of activating social movements to overcome the common problem. However, it contributes to the relocation of communications into the virtual environment [11].

However, the existing drawbacks in communication between the authorities and society and close to critical mistrust level in state institutions and information emanating from them will hamper such activation. And this is in a situation where a large part of the population needs help and support, including due to the loss of previously common forms of communication that have become less accessible under quarantine restrictions.

Between 2016 and 2018, the International Centre for Defense and Security (ICDS) conducted "Resilient Ukraine," a project regarding civil society and national security [12]. It combined field research (survey) and analytical work regarding legislation and government action plans in national security, statistical data representations, etc.

The survey's results and the analysis of Ukrainian legislation and government action plans in the field of community resilience and communications help us identify the main gaps between state institutions and civil society due to an excessively centralized system of power taking place in Ukraine for decades. As a result, the financial, symbolic, and other resources are concentrated in Kyiv and are constantly exhausted from the regions. In turn, regions do not receive enough economic and social capital to implement their functions completely. One of the main gaps between healthcare institutions and citizens is a communication gap.

The pandemic spread exacerbated the situation even more because of the threat to your own and your relatives' health and lives, the state of uncertainty and insecurity caused by the disease unpredictability, and the limitation of traditional in Ukraine contacts with relatives, friends, and colleagues due to quarantine. It aroused increased interest in the information capable of clarifying the situation, suggesting 